\title{
Surco perineal en ginecología infantil: reporte de 2 casos clínicos
}

\author{
CAROLINA PASTENE S. ${ }^{1}$, FRANCISCA ROJAS M. $^{2}$ \\ 1. Unidad de Ginecología Infantil y del Adolescente. División de Obstetricia y Ginecología, Facultad de Medicina, \\ Pontificia Universidad Católica de Chile. \\ 2. Residente de Medicina Familiar del Niño. Facultad de Medicina, Pontificia Universidad Católica de Chile.
}

\begin{abstract}
Perineal groove in pediatric gynecology: a report of 2 cases

Introduction: The perineal groove is a very uncommon anorectal anomaly. It is the result of an unknown embryology anomaly. The perineal groove is a wet sulcus extending from de fourchette to the anus. It is a benign pathology and tends to resolve spontaneously. Objective: We report two cases of girls diagnosed with perineal groove and their follow up. Cases reports: The first case is an 18 days old baby girl, that during her first clinical examination there was found a painless lineal lesion in the perineum from the fourchette to the anus, which created a big anxiety in her family. She was cared at the Pediatric Gynecology Unit, with local lubrication, doing well with the epithelization of it. The second case is an 8 year-old girl who consulted because, when being a child, she was diagnosed with a perineal lesion, but she didn't receive any special treatment and now she feels some aches in the perineum. Conclusions: The perineal groove is a benign entity pretty unknown by general practitioners or pediatricians. It is important to be up to date with this condition to avoid alarming misinterpretations.
\end{abstract}

(Key words: Perineal groove, perineal fissure, anorectal malformation, sexual abuse).

Rev Chil Pediatr 2014; 85 (4): 486-490

\section{RESUMEN}

Introducción. El surco perineal es una malformación poco frecuente, de etiología desconocida, consiste en una ranura en la línea media del periné desde la horquilla vulvar al ano, es benigna y tiende a la resolución espontánea. Objetivos: Reportar el diagnóstico y evolución de dos pacientes con surco perineal. Casos Clínicos: Caso 1. Recién nacida de 18 días que previo al alta de maternidad se pesquisó una lesión lineal no dolorosa desde la horquilla vulvar al ano, lo que generó gran inquietud en su familia. En Ginecología Infantil se confirmó el diagnóstico, se manejó con lubricación del área genital evolucionando a la epitelización del surco. Caso 2. Niña de 8 años consultó por que en controles de salud se diagnosticó una "fisura" entre la horquilla vulvar y el ano que no fue tratada y presentaba molestias inespecíficas en el periné. Se indicó resección quirúrgica, pero

Recibido el 25 de enero de 2014, última versión aceptada para publicación el 20 de julio de 2014.

Potenciales conflictos de interés: Este trabajo cumple con los requisitos sobre consentimiento /asentimiento informado, comité de ética, financiamiento, estudios animales y sobre la ausencia de conflictos de intereses según corresponda. 
paciente evolucionó satisfactoriamente con lubricación de la zona. Conclusiones. El surco perineal es una entidad benigna que debe ser conocida por médicos de atención ambulatoria debido a la alarma que pueden generar sus diagnósticos diferenciales.

(Palabras clave: Surco perineal, ranura perineal, malformación anorrectal, abuso sexual).

Rev Chil Pediatr 2014; 85 (4): 486-490

\section{Introducción}

El surco perineal o "perineal groove" en la literatura inglesa, corresponde a una malformación anorrectal (MAR), que consiste en una ranura en la línea media del periné desde la horquilla vulvar hasta el ano, cubierto por mucosa rojiza, sin epitelio cuya longitud como profundidad pueden ser variables ${ }^{1}$.

Las MAR representan un amplio espectro de defectos, con grados variables de complejidad pudiendo involucrar al ano y al recto como a la vía urinaria y los genitales. Las MAR son una anomalía congénita que presenta una incidencia estimada de 1 por 4000 a 5000 recién nacidos $(\mathrm{RN})$ vivos. Existe un ligero predominio de hombres respecto de las niñas, con una relación de 1,4-1,6:12.

La etiología de las MAR es aún desconocida y lo más probable es que tenga un origen multifactorial, hay algunos síndromes genéticos en los cuales son más frecuentes así como en algunas familias.

Históricamente, se han agrupado de acuerdo al abordaje quirúrgico de éstas, clasificando las lesiones en: bajas, intermedias y altas, según la distancia entre el fondo de saco ciego rectal con la región perineal. Frecuentemente se asocian a otras malformaciones, por ejemplo, genitourinarias en un $50 \%$, anomalías espinales o cardíacas hasta en un $8 \%{ }^{2}$. Dado que el ano es normal en las pacientes con surco perineal, esta condición se clasifica como una MAR baja.

El diagnóstico de las MAR es principalmente clínico, siendo clave la inspección de las nalgas y el periné. Se debe identificar la posición del ano y la normalidad de los genitales, en la niña se debe localizar el meato urinario y el himen en el vestíbulo. El estudio se complementa con ultrasonido abdominal, radiografía de columna lumbosacra o resonancia magné- tica. En el caso del surco perineal, la mayoría de los pacientes no presenta otras alteraciones asociadas, por lo que el diagnóstico es clínico sin necesidad de realizar estudios de imágenes.

Se desconoce la incidencia real del surco perineal, dado que es una patología poco reportada por los clínicos, debido al leve impacto que produce en la vida de las pacientes. Generalmente evoluciona con epitelización espontánea y no requiere de un tratamiento específico.

$\mathrm{Su}$ importancia radica en que sus características pueden confundirse con otras alteraciones dermatológicas o sospecha de abuso se$\mathrm{xual}^{3}$, lo que puede inquietar tanto a los padres como al personal de salud poco familiarizado con este diagnóstico.

El objetivo de este artículo es reportar dos casos clínicos sobre este tema que no ha sido previamente tratado en la literatura médica nacional.

\section{Caso clínico 1}

Paciente de sexo femenino, 18 días de vida con antecedentes de ser una nacida de término por cesárea, de un embarazo fisiológico. Sus padres consultaron a la Unidad de Ginecología Infantil por la presencia de una abertura entre la vagina y ano detectada al nacimiento que evolucionó asintomática. Al examen físico general se constató una paciente en buen estado nutricional y en la evaluación dirigida de los genitales destacaron los labios mayores prominentes, himen rosado redundante y permeable. El periné presentaba una lesión lineal entre la horquilla vulvar y el ano, con el aspecto de una lesión cortante cubierta por mucosa eritematosa con el orificio anal de aspecto y posición normal (figuras 1 y 2). Se palpó botón mamario sin galactorrea y el resto del examen general estaba dentro de límites normales. Se 


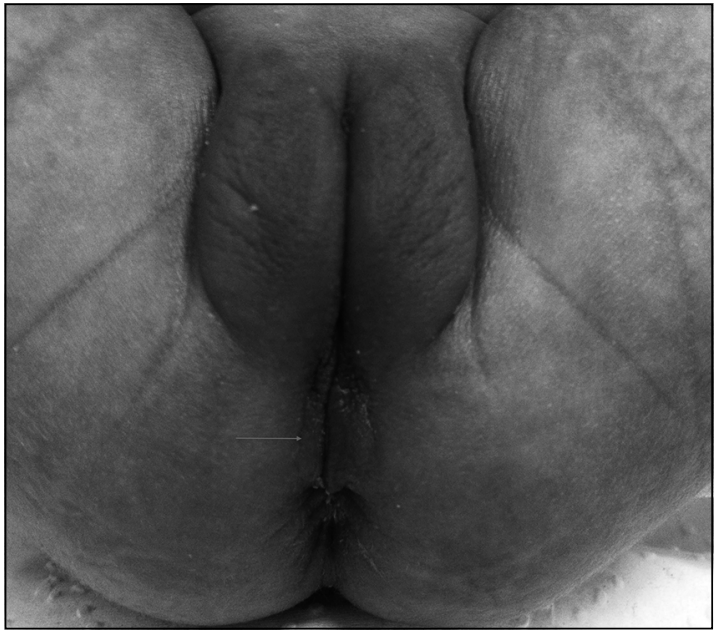

Figura 1. Surco perineal en niña de 18 días en reposo.

indicó aseo con agua y lubricación con vaselina sólida en cada muda. En el control de los 4 meses la madre señaló que la lesión había evolucionado sin complicaciones y al examen físico se constató epitelización del surco perineal (figura 3).

\section{Caso clínico 2}

Escolar de sexo femenino, 8 años de edad, consultó junto a su madre por ardor en el área genital y perineal asociado a una secreción blanca, sin mal olor, diariamente por dos semanas aproximadamente. Tenía el antecedente de haber presentado una fisura anogenital desde período de lactante que se mantuvo en observación por un período breve sin completar el seguimiento hasta el alta. La paciente realizaba su aseo genital diariamente sólo con agua presentado en dos ocasiones sangrado escaso al secar zona perineal. Sin antecedentes de infección urinaria, constipación, ni de desarrollo puberal.

Al examen la paciente se encontraba eutrófica, con mamas y vello púbico en Tanner I. En el examen genital se observó un himen redundante permeable, rojo, y un surco mucoso desde la horquilla vulvar hasta el ano, sensible al tacto. Se diagnosticó un surco perineal asociado a una vulvovaginitis inespecífica. Se tomaron muestras para cultivo vaginal cuyo resulta-

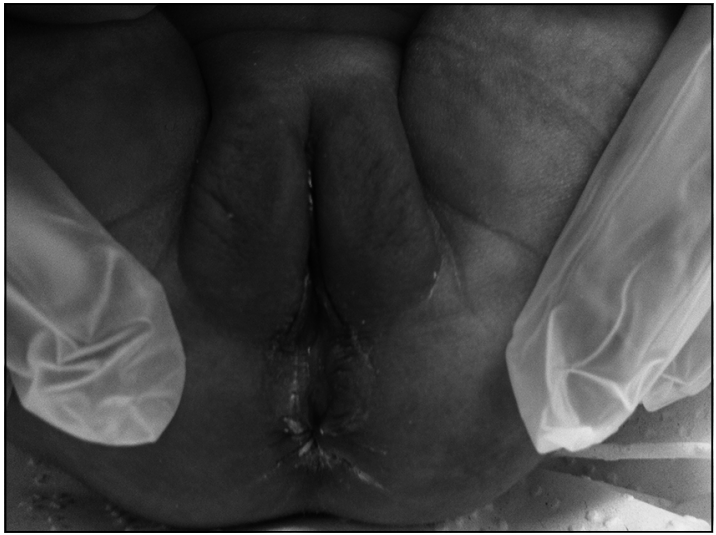

Figura 2. Surco perineal en niña de 18 días con tracción de los glúteos.

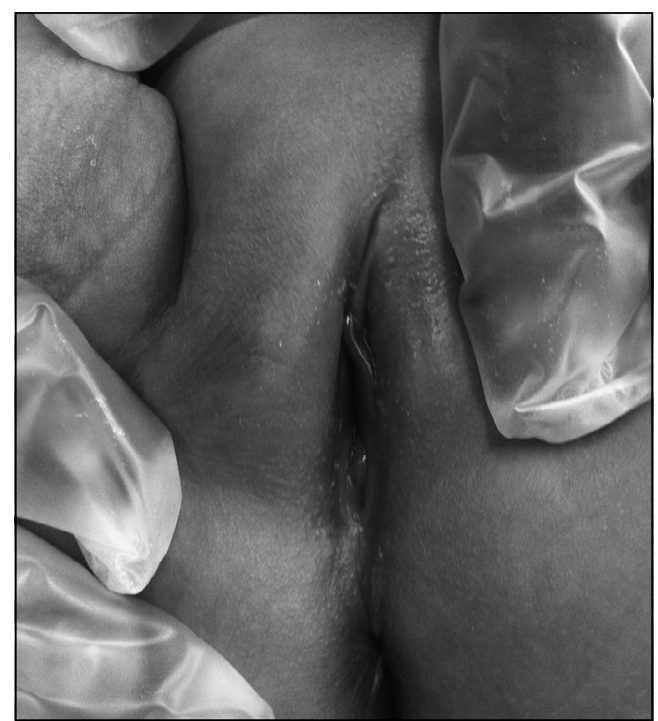

Figura 3. Surco perineal epitelizado a los 4 meses de edad.

do arrojó flora comensal. Se sugirió resección quirúrgica del surco, pero la familia decidió realizar una prueba terapéutica con lubricantes tópicos, dado que entendió el carácter benigno de la lesión.

\section{Discusión}

El surco perineal se define como una forma mínima de MAR cóngenita baja ${ }^{1}$. Se caracteriza por presentar 3 condiciones: ser un surco húmedo en el periné entre la horquilla vaginal 
y el ano, formación normal del vestíbulo incluyendo uretra y vagina, e hipertrofia de los labios menores que se extienden por los bordes del surco, a veces incluyendo el ano ${ }^{4}$.

Se desconoce su incidencia y prevalencia real. En cuando a su distribución por género, los casos reportados en la literatura internacional corresponden a mujeres, y hay un solo caso publicado en un niño, cuya malformación estaba asociada a una hipospadia y escroto bífido ${ }^{5}$.

El origen embriológico del surco perineal es incierto. Durante los años se han planteado distintas hipótesis, una de ellas postula que sería producto de una alteración en la fusión o fusión distorsionada de los pliegues genitales mediales o del rafe; también se ha propuesto ser una alteración temprana en el desarrollo de la cloaca del embrión o un defecto en el desarrollo del septo uroanal ${ }^{4,6}$.

Histológicamente, en el surco perineal se observa piel modificada y ausencia de vello y apéndices, similar a las estructuras de los pliegues genitales medios (pecten y labios menores) $)^{4}$.

El diagnóstico es clínico, y éste se puede confundir con un hemangioma ulcerado, dermatitis del pañal ${ }^{7}$, infección, liquen escleroso, protrusión piramidal perianal, trauma o abuso sexual.

Normalmente no se asocia a otras malformaciones por lo que no es necesario solicitar imágenes o exámenes invasivos para hacer el diagnóstico y tranquilizar a los padres ${ }^{8}$.

Respecto a la sintomatología se ha descrito defecación dolorosa, fisura anal, prurito y descarga mucosa perineal persistente ${ }^{9}$, sin embargo, en la mayoría de los casos el surco perineal no suele causar molestias que limiten significativamente la vida diaria del paciente, salvo cuando se asocia a otras malformaciones, como hipospadia. La evolución natural es a la epitelización espontánea al cabo de meses o años ${ }^{2}$. Las complicaciones reportadas corresponden a vulvitis e infecciones urinarias, constipación secundaria, ectropion anal y en la vida adulta cuadros de vulvodinea/dispareunia9 ${ }^{9}$.

En este contexto, la mayoría de los autores que han estudiado estos casos recomiendan un manejo expectante, con uso de lubricantes tópicos sin necesidad de una intervención qui- rúrgica, la que de realizarse debería ser idealmente después de los 2 años de edad, cuando ha pasado tiempo suficiente para la epitelización y no se estén utilizando pañales.

La resección del surco estaría indicada por razones estéticas, o por persistencia de síntomas como ardor o infecciones por gérmenes rectales. Un estudio italiano ${ }^{10}$ comparó la evolución clínica frente a dos técnicas quirúrgicas en 6 niñas con diagnóstico de surco perineal de entre 2 y 7 años de edad. En tres pacientes se realizó resección del surco y cierre de éste con sutura interrumpida, y en las otras tres niñas se realizó lo mismo agregando un adhesivo químico sobre la sutura. Todas las niñas del primer grupo, presentaron dehiscencia de la herida operatoria por contaminación con orina y/o deposiciones a diferencia de las niñas en que se complementó la sutura con adhesivo.

Dado estos datos es que sugerimos a nuestra segunda paciente, que persiste con ardor, secreción mucosa y sangrado intermitente del periné, la alternativa quirúrgica para la resolución de sus molestias actuales.

\section{Conclusión}

El surco perineal, es una entidad poco conocida por pediatras y médicos de atención ambulatoria, por lo que es necesario familiarizarse con su existencia, para evitar confusiones en el diagnóstico generando alarma, así como gastos innecesarios en extensas evaluaciones o procedimientos quirúrgicos prematuros.

\section{Agradecimientos}

A Dr. José Andrés Poblete y Paola Casanello por revisión del manuscrito.

\section{Referencias}

1.- Stephens FD: The female anus, perineum and vestibule: Embriogenesis and deformities. Aust N Z J Obstet Gynecol 1968; 8: 55-73.

2.- Levitt MA, Peña A: Review Anorectal malformations. Orphanet Journal of Rare Disease 2007; 2: 33. 
3.- Carrera Polanco M: Perineal groove, o cómo un hallazgo pequeño puede convertirse en un problema grande. Rev Pediatr Aten Primaria 2012; 14: 323-6.

4.- Sekaran P, Shawis R: Perineal groove: A rare congenital abnormality of failure of fusion of the perineal raphe and discussion of its embryological origin. Clin Anat 2009; $7:$ : 823-5.

5.- Chatterjee SK, Chatterjee US, Chatterjee U: Perineal Groove with penoscrotal hypospadias. Pediatr Surg Int 2003; 19: 554-6.

6.- Mullassery D, Turnock R, Kokai G: Perineal Groove. J Ped Surg 2006; 41: E41-3.
7.- Verma SB, Wollina U: Perineal Groove-A case report. Pediatric Dermatology 2010; 27: 626-7.

8.- Díaz L, Levy M, Kalajian A, Metry D: Perineal Groove: A report of 2 cases. Doi:10.1001/jamadermatology. 2013.4613.

9.- Jesús LE: Calha Mucosa Perineal (Perineal Groove)Variante Clínica de Malformação Anoretal. Rev bras Coloproct 2004; 24 (4): 308-10.

10.- Esposito C, Giurin I, Savanelli A, Alicchio F, Settimi A: Current Trends in the Management of Pediatric Patients with Perineal Groove. J Pediatr Adolesc Gynecol 2011; 24: $263 \mathrm{e}-5$. 